Mirai. Estudios Japoneses

ISSN-e: 2531-145X

https://dx.doi.org/10.5209/mira.63110

\title{
La presencia de Hokusai en la prensa española (1868-1926): biografía, obra y valoración crítica.
}

\author{
Pablo César Anía Ruiz-Flores ${ }^{1}$
}

Resumen. En el presente artículo se trata el impacto de Hokusai en España a través de las publicaciones periódicas en el último tercio del siglo XIX y primeras décadas del siglo XX coincidiendo con los periodos japoneses Meiji (1868-1912) y Taishō (1912-1926), época en la que el arte japonés y el fenómeno del japonismo se encontraban en pleno auge. El impacto de Hokusai en nuestro país a través de las publicaciones periódicas no fue tan importante como el que se produjo en otras naciones occidentales que tuvieron en esta época vínculos más estrechos con Japón y donde el coleccionismo de arte japonés (en especial de grabados ukiyo-e) fue más notorio. No obstante, tanto en revistas ilustradas como en buena parte de los periódicos nacionales y locales españoles se hicieron eco de la importancia de este destacado artista japonés proporcionando noticias sobre su vida y su obra, además de brindar informaciones sobre su influencia en otros artistas y sobre el coleccionismo de sus obras. De esta forma el conocimiento tanto de Hokusai como de su obra gozó de una notable difusión alcanzando todos los estratos de la sociedad y presentando un gran calado.

Palabras clave: Japón; japonismo; España; Hokusai; prensa.

\section{[en] The presence of Hokusai in the Spanish press (1868-1926): biography, work and critical appraisal.}

\begin{abstract}
This article analyzes the impact of Hokusai in Spain as reflected in periodic publications during the last third of the nineteenth century and the first decades of the twentieth century which coincided with the Meiji (1868-1912) and Taishō (1912-1926) periods in Japan. It was the heyday of Japanese art and the phenomenon of japonism. The impact of Hokusai in Spain as seen in these periodic publications was not as major as that witnessed in other western nations which had closer ties with Japan and where the collection of Japanese art (especially of ukiyo-e prints) was more important. Nevertheless, the importance of Hokusai as a prominent Japanese artist was in fact echoed in illustrated magazines, and in a great part of national and local newspapers of Spain. These published news regarding his life and his work, in addition to offering information about his influence on other artists as well as reporting the collecting of his works. In this way the knowledge of both Hokusai and his work enjoyed a remarkable diffusion reaching all strata of Spanish society indicating the amplitude of his influence.
\end{abstract}

Keywords: Japan, japonism, Spain, Hokusai, press.

Cómo citar: Anía Ruiz-Flores, P. C. (2019). La presencia de Hokusai en la prensa española (18681926): biografía, obra y valoración crítica, en Mirai. Estudios Japoneses 3(2019), 145-165.

\footnotetext{
Universidad de Zaragoza.

E-mail:pcania92@gmail.com
} 
Las relaciones de Japón y España en la época del japonismo no fueron tan intensas como las que establecieron otras naciones occidentales. Aunque el inicio oficial de las relaciones con Japón tuvo lugar en 1868, fecha en la que ambos países firmaron el primer Tratado mutuo de amistad, comercio y navegación, la compleja situación política, social y económica que vivió la España de aquella época impidió que se establecieran unas sólidas relaciones comerciales y diplomáticas entre nuestro país y el archipiélago nipón y que fraguasen estrechos vínculos a nivel artístico y cultural. Durante mucho tiempo se creía que tales relaciones habían sido puntuales y casi anecdóticas. Sin embargo, tal y como han revelado los últimos estudios realizados sobre la materia, en nuestro país y durante esta época, ${ }^{2}$ Japón, su cultura y su arte, tuvieron una presencia y un impacto que si bien no fueron tan intensos como lo que hubo en otros países de Occidente fueron más que significativos.

Así por una parte, sabemos que llegaron hasta España piezas de arte nipón por muy diferentes vías. Casos excepcionales son las obras traídas personalmente por viajeros españoles que visitaron o residieron en el País del Sol Naciente, ya que fueron muy pocos. Gran parte de los objetos artísticos japoneses que llegaron a nuestro país en la segunda mitad del siglo XIX y primeras décadas del XX fueron adquiridos en diversas capitales europeas (sobre todo en París) por españoles (artistas, literatos, empresarios y comerciantes). Sin embargo, buen número de piezas pudieron ser compradas en tiendas del país, cuyos dueños las importaron a su vez de distintas ciudades de Europa y, con el tiempo, del mismo Japón. Las investigaciones realizadas hasta ahora ${ }^{3}$ han puesto en evidencia que se abrieron numerosas tiendas y establecimientos en nuestra geografía donde se vendía arte japonés, en especial en Madrid y, sobre todo, en Barcelona.

Esta tendencia japonista manifestada en la España de finales del siglo XIX y principios del XX se verá totalmente reflejada en las publicaciones periódicas del momento. Así pues, hemos podido localizar multitud de revistas y de periódicos publicados en España entre 1868 y 1926 que tratan la figura de Hokusai. ${ }^{4}$ Apareciendo el nombre del maestro nipón en textos de la más diversa índole como pueden ser escritos de carácter artístico y académico, pero también de tipo bélico, catastrófico, paisajístico, culinario, musical o teatral.

En esta ocasión y debido a la temática variada en las que se incluye el creador nipón nos centraremos en las noticias que tratan su biografía, valoración y obra. La primera referencia que nos sirve de punto de partida la encontramos en el Diario oficial de avisos de Madrid en el año $1883 .{ }^{5}$ En esa fecha se dedica un artículo al arte nipón en general, que muestra una opinión muy positiva sobre el mismo, otorgándole un estatus superior que al arte chino. Su autor anónimo, no obstante, incurre en algunos errores que denotan su desconocimiento de la historia de Japón. Afirma que los japoneses tienen una nación con entidad propia cuyo desarrollo artístico y literario, se inició en el siglo VI. Según el autor, el periodo japonés verdaderamente floreciente es el que comenzó en 1184 con "Yoritoma" que se instaló en Yedo; quien fue

\footnotetext{
Barlés, E. (2010): 154-171.

Bru, R. (2008): 153-170.

Un total de cuarenta y ocho publicaciones localizadas entre los fondos de diversas hemerotecas.

Anónimo (1883): “El arte japonés”, Diario oficial de avisos de Madrid, Madrid, 30/11/1883, p. 3.

En realidad se refiere a la figura de Minamoto Yoritomo (1147-1199), fundador del gobierno militar de Kamakura. Hace alusión a la actual ciudad de Tokio, conocida antiguamente como Edo, lo cual es un error porque se instaló en Kamakura.
} 
sucedido mucho más tarde por Ota Nobunaga,${ }^{8}$ del que dice que ocasionó la ruina a los jesuitas que fueron a Japón. ${ }^{9}$ Más acertado está el autor al comentar hechos más contemporáneos. Considera a los japoneses como una raza inteligente y viva, que ama la naturaleza y los goces de la vida doméstica y que destaca por gusto estético, faceta que se aprecia en las decoraciones de sus hogares con pinturas realizadas en seda y papel, lacas y porcelanas. Señala que en 1868 los japoneses empezaron a remitir a los mercados europeos multitud de objetos, donde son muy apreciados. En concreto, señala que es en Inglaterra donde más se estima la pintura japonesa y comenta que el Museo Británico adquirió la colección del doctor Anderson compuesta de dos mil piezas, ${ }^{10}$ mientras que en Berlín resalta la colección del doctor Gierke. ${ }^{11}$ De los pintores japoneses del siglo XVIII destaca a Hokusai a quien, a pesar de que pertenece a una escuela "vulgar", compara con artistas fundamentales en el desarrollo del arte en Europa como Rembrandt, Callot, Goya y Daumeir. ${ }^{12}$

Este artículo demuestra que ya tempranamente se tenía una excelente opinión sobre el creador nipón, que probablemente recoge la tónica que había marcado la historiografía francesa a partir de los años sesenta del siglo XIX. El artículo tuvo tanto éxito que el Diario oficial de avisos de Madrid decidió publicar al año siguiente el mismo escrito, cuyo contenido se amplió, haciendo referencia a otros formatos pictóricos nipones como los kakemono, los emakimono y los álbumes (e-hon) ${ }^{13}$ Esto refleja la aceptación que debían de tener esta clase de artículos relacionados con el arte japonés y, en concreto, sobre la figura de Katsushika Hokusai, ya que se debieron de percibir como una gran novedad para una población acostumbrada a otro tipo de noticias.

Esta valoración de Hokusai es la que arraigará y se mantendrá, salvo excepciones, en nuestro país. Siete años más tarde, en 1891, encontramos por primera vez en $L a$ Ilustración Ibérica, un artículo dedicado monográficamente a Hokusai. ${ }^{14}$ Este hecho posiblemente se deba a la relevancia que estaba empezando a tomar su figura desde el ámbito artístico. De nuevo en este texto se ofrece una idea positiva del artista, una valoración que debió de influir en la sociedad del momento, en esa clase media ávida de conocimiento, ya que cualquier artículo de esta índole suscitaba intriga por descubrir nuevos mundos. ${ }^{15}$ En él ya se destacan dos aspectos fundamentales que prevalecerán en las noticias que ensalcen el arte del pintor japonés. Por un lado el concepto de genio renovador, aquel que dio un giro a la pintura y consiguió enriquecer el género ukiyo-e, y, por otro, la idea de su maestría como ilustrador de libros. De hecho, en las siguientes décadas una de las obras a las que se le dedicará mayor atención serán sus libros ilustrados conocidos como Manga. Una particularidad de este artículo es que

8 Se refiere a la figura de Oda Nobunaga (1534-1582), uno de los señores feudales o daimyō de la historia de Japón que gobernó parte del periodo Sengoku y Momoyama.

$9 \quad$ Nuevamente incurre en un error ya que Oda Nobunaga fue partidario de la presencia extranjera (incluidos los misioneros) durante el periodo Namban (1543-1615).

10 Efectivamente el Museo Británico cuenta con la colección de más de 2.000 pinturas japonesas y chinas reunidas por el profesor William Anderson durante su residencia en Japón en 1873-1880. Fue adquirida por el Museo en 1881. Anderson, William (1886).

11 Probablemente se refiere al filósofo Otto Friedrich von Gierke (1841 - 1921) que tuvo una importante colección de arte nipón. Spang, Christian / Wippich, Rolf-Harald (2007): 134.

12 Anónimo (1883): "El arte...", op. cit., p. 3.

13 Anónimo (1884): “El arte japonés”, Diario oficial de avisos de Madrid, Madrid, 19/02/1884, p. 3.

14 Anónimo (1891): “El pintor japonés Hokusai”, La Ilustración Ibérica, Barcelona, 12/09/1891, p. 587.

15 Ibidem. 
en la publicación se insertan las imágenes de varias obras pertenecientes a Hokusai, ${ }^{16}$ despertando con ello la curiosidad de los lectores [fig. 1].

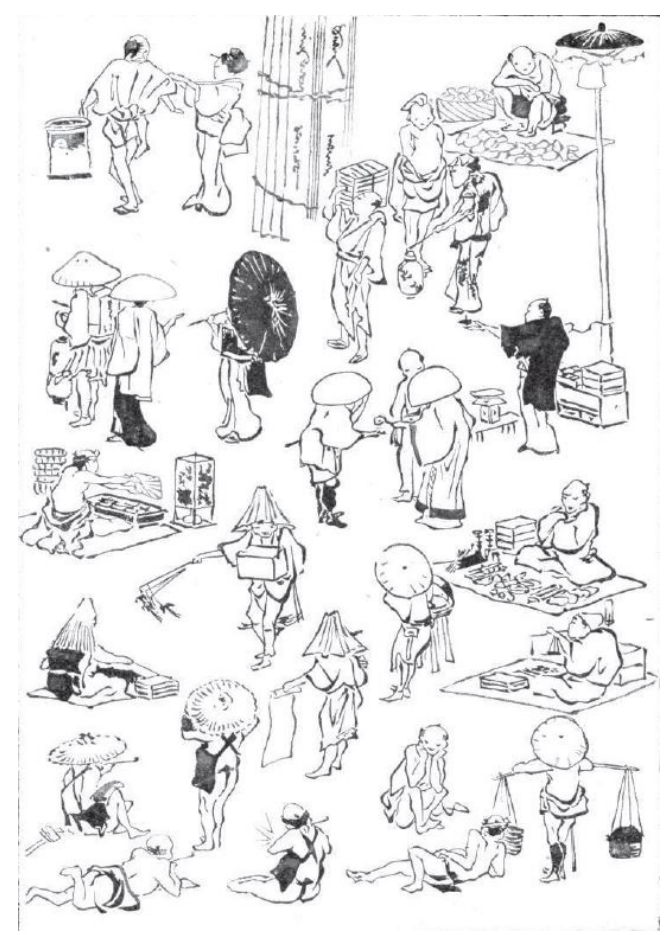

Fig. 1: "El pintor japonés Hokusai”, La Ilustración Ibérica, Barcelona, n. ${ }^{\circ} 454$, 12/09/1891, p. 588.

También era muy habitual en la época realizar comparativas o establecer relaciones entre las obras de artistas -tanto nacionales como extranjeros- con la figura de Hokusai, con el fin de ensalzar a los primeros. Un artículo, pionero en estas comparaciones fue el publicado en 1892 en el periódico La época ${ }^{17}$ por Rodrigo Soriano (1868-1944) en el que se trató la figura de Adam Adolf Oberländer (1845-1923), un importante caricaturista alemán nacido en Ratisbona que desarrolló gran parte de su carrera en Múnich haciéndose famoso a través de sus parodias humorísticas. ${ }^{18}$ En este caso se dice que el lápiz del alemán era como una "varita mágica" que ejecutaba las complejas ideas albergadas en su mente, lo que evocaba a la obra de Hokusai. Este modo de analogías y nexos de unión hacen que el lector relacione el buen hacer del japonés con la obra del artista, consiguiendo de esta forma automáticamente que su obra ocupe un lugar de mayor preeminencia de cara al público.

16 Aparece una imagen en la que se reproduce el tomo VIII del Manga datada en 1817, una pintura de un surimono datada en 1800, una perteneciente a una novela titulada Kata que la datan en 1795, Curiosidad excitada por la llegada de los europeos en el siglo XVII datada en 1799, una de la $<<$ Oigwa $>>$ datada en 1802 y por último dos obras más, una denominada Niñas rivales y otra Cruzando un río datadas en 1813.

17 Soriano, R. (1892): “Oberländer”, La época, Madrid, 05/06/1892, p. 2.

18 Consúltese: Europeana (2008): Europeana Collections [https://www.europeana.eu/portal/en], European Union's Connecting Europe Facility. https://www.europeana.eu/portal/en/explore/people/50327-adolf-oberlander.html, [Consulta: 18/10/2017]. 
Pero no todas las referencias a la figura del creador nipón se incorporaron en noticias de tono amable o académico, sino que también sirvieron en ocasiones para arremeter contra ciertas situaciones políticas o para apoyar el auge del nacionalismo periférico, en apogeo en aquellos momentos. Este es el curioso caso de un artículo de claro tinte catalanista publicado en 1897 en la revista La Renaixensa, en el que se realiza una reflexión sobre la pérdida de Cuba y cómo esta situación estaba afectando a la España "centralista". En él se subrayan los logros de Cataluña en el campo de la sanidad o del urbanismo, con ejemplos como "el ensanche", en contraposición con lo que ocurre en otras partes del país. Es en este contexto el autor critica un artículo publicado en El Globo por el periodista madrileño Navarro y Ledesma (1869-1905), ${ }^{19}$ en el que se denigraba a los creadores japoneses en pro de los primeros artistas españoles. ${ }^{20}$ Tales declaraciones sirvieron a nuestro escritor anónimo para argumentar la "necedad" y retraso de algunos círculos madrileños. ${ }^{21}$ El texto, en cualquier caso, refleja la alta estima que se le tenía al arte japonés en el ámbito catalán y sobre todo a Hokusai, quien es utilizado a modo de excusa para contraponer dos ámbitos culturales que se aprecian como opuestos, el catalán, con vocación de modernidad, y el madrileño, arraigado en el pasado. Tan solo tres días más tarde, de nuevo, en $\mathrm{La}$ Reinaixensa se vuelve a publicar un artículo en el que otra vez se critican las opiniones negativas emitidas por algunas figuras literarias madrileñas en relación con las manifestaciones artísticas de Japón. En el texto se achaca este odio o rechazo hacia el arte japonés a fenómenos como el colonialismo y las guerras coloniales. Desde el nacionalismo catalán, por el contrario, se ensalza de manera ferviente el arte nipón y por ende a la figura del genio Hokusai. ${ }^{22}$

Fue en esta época de cambio de siglo cuando la expansión de la moda de lo japonés en España comenzó a cobrar verdadera fuerza. Ante la continua presencia de lo nipón, sobre todo en los circuitos artísticos, debieron formarse dos frentes: los que apoyaban de manera incondicional el valor y legitimidad de su arte y los que desestimaban tales producciones anteponiendo lo local y nacional. En esta última línea se encuentra un artículo ciertamente controvertido. Fue publicado en El nuevo ateneo de Toledo en $1889^{23}$ y redactado por el diplomático español Juan Pérez Caballero y Ferrer (1861-1951), del que sabemos estuvo en Japón en 1888 y que era buen conocedor del comercio que España tenía con el archipiélago. ${ }^{24}$ En este, trata al arte japonés como un desconocido para la población y afirma que los objetos nipones estaban sobrevalorados injustamente, ya que se pagaba más por ellos de lo que se debería, teniéndoseles una estima excesiva. El autor así deja claro su posicionamiento arremetiendo contra este tipo de estética de manera directa. Además, cita a figuras que fueron clave para la expansión del gusto por el País del Sol Naciente. Personalidades tales como Goncourt, Gonse, Bing y Cernuschi, las cuales habían intentado desviar la mirada hacia el arte de las islas del este y otorgarles el valor que debería haber tenido desde el principio, siendo este un valor netamente secundario; valor que según

\footnotetext{
Controvertido periodista y crítico literario. Serrano, J. (2006).

Anónimo (1897): “Barcelona”, La Renaixensa, Barcelona, 07/01/1897, p. 129.

Ibidem.

Anónimo (1897): "Barcelona”, La Renaixensa, Barcelona, no 7480, 09/01/1897, p. 171.

Pérez Caballero, J. (1889): “Adiós al Japón”, El nuevo ateneo, Toledo, 15/11/1889, p. 137.

24 Fue autor de la siguiente obra: Pérez Caballero, J. (1888): "Estudio práctico sobre nuestros intereses en el Japón según la base que ofrece la estadística general del comercio exterior del Imperio en el año 1887", Boletín de la Sociedad Geográfica de Madrid, Madrid, 1888, pp. 324-362. Este texto fue firmado en Tokio en 1888.
} 
nuestro autor era el que les correspondía. En este argumento encontramos a Hokusai descabalgado de su fama y gloria preeminente como genio creador. ${ }^{25}$

Hay que recordar que a principios del siglo XX Japón vivió uno de los acontecimientos que marcaron su desarrollo político y militar. Así pues, entre los años 1904-1905 tuvo lugar la guerra-ruso japonesa, evento que hizo que los medios internacionales pusieran sus miradas sobre Japón y aumentará el interés por el País del Sol Naciente. En esas fechas, en España, todavía existían férreos defensores del Academicismo que no comprendían aquellos artistas que habían emprendido la búsqueda e investigación de nuevas vías de expresión y descubrimiento de nuevos artes, como el japonés, los cuales sirvieron como elementos germinadores de estéticas alternativas. Todavía había personalidades e intelectuales que se resistían a los cambios y que valoraban más lo nacional y lo propio que lo nuevo y renovador. Así podemos interpretar el mensaje de nuestro escritor de una forma directa, ya que para él confiar y valorar el arte japonés es un error que va en detrimento de lo que era la tradición artística propia. La primera referencia a Hokusai en el siglo XX la encontramos en la temprana fecha de 1902 en Alrededor del Mundo, aquí aparecen figuras de su famoso Manga a modo de pasatiempo, donde los lectores tenían que encontrar una solución al rompecabezas que se les planteaba. ${ }^{26}$ Además a las dos semanas se publicó la solución para la tranquilidad de los lectores. ${ }^{27}$

Ya en 1904, en el Boletín de la real sociedad geográfica se publica un artículo, bajo el título "El imperio del Japón". ${ }^{28}$ En este texto se comenta, entre otros temas, la figura de Hokusai, realizando una valoración negativa del mismo. En él su autor, Juan Mencarini Pierroti (1860 -1939), ${ }^{29}$ empleado en las Aduanas Imperiales (Chinese Maritime Customs Service), que vivió largos años en China, intenta relativizar la generalizada pasión que producía la estética del pintor japonés, desconocida hasta hace poco tiempo. Así señala que, a pesar de que en los últimos años la atención pública de Europa se había sentido atraída por el arte nipón, para él es estrafalario y grotesco y está en contra de que se le llame "nuevo arte". 30

Como contrapunto a la noticia anterior, tenemos al guatemalteco Enrique Gómez Carrillo (1873 -1927), insigne escritor modernista quien escribió numerosos artículos para el periódico El Liberal. Gómez Carrillo fue por sus escritos una de las figuras más relevantes en la difusión del arte japonés y la cultura nipona en el ámbito hispanoparlante. Las fuentes que le llevaron a alcanzar un conocimiento de Japón fueron múltiples: desde la lectura de libros sobre Japón y su arte publicados en Europa en aquella época, sus contactos con comerciantes y artistas de París (lugar en el que residió largas temporadas) hasta su viaje al archipiélago nipón. Tal era su conocimiento que escribió para El Liberal en $1904^{31}$ un completísimo

Pérez Caballero, Juan (1889): “Adiós al...”, op. cit., p. 137.

26 Anónimo (1902): "Los japoneses y el cabestrante", Alrededor del Mundo, Madrid, 13/02/1902, p. 113. Artículo recogido en: Almazán, D. (2000): p. 63.

27 Anónimo (1902): “La solución”, Alrededor del Mundo, Madrid, 27/02/1902, p. 141. Artículo recogido en: Almazán, D. (2000): Japón y el japonismo..., op. cit., p.63.

28 Mencarini, J. (1904): “El imperio del Japón”, Boletín de la real sociedad geográfica, Madrid, 01/01/1904, p. 44.

29 Universidad Abierta de Cataluña (2014): Archivo China-España 1800-1950 [http://ace.uoc.edu/], ALTER/UOC. http://ace.uoc.edu/exhibits/show/galeria-de-personajes/juan-mencarini [Consulta: 14/11/2017].

30 Mencarini, J. (1904): “El imperio del...”, op. cit., p. 44.

31 Gómez Carrillo, E. (1904): "Los pintores japoneses en el museo del Louvre”, El liberal, Madrid, 18/02/1904, p. 3 . 
artículo sobre los pintores japoneses que se encontraban en el Museo del Louvre de París, realizando una valoración crítica excelente de Hokusai, como una de las principales figuras del género ukiyo-e. En su texto constata la moda ferviente que suscitaba Japón en la Europa de principios del siglo XX. Una sociedad que veía parte de su renovación en lo exótico, en lo lejano, en esas maravillas llegadas desde el otro extremo del globo y que parecían estar representando lugares de ensueño. Según este autor, obras de arte japonés se encontraban frecuentemente en los establecimientos y librerías. En especial en Francia esta pasión era evidente. Prueba de ello fue que incluso se creó en el museo más representativo de la capital del Sena, ciudad pionera en la penetración del arte nipón, una sala exclusiva dedicada a este arte con lo más selecto del género de la estampa japonesa. ${ }^{32}$ A continuación, destaca la figura de Hokusai del que señala el rasgo que define su obra como es su veneración por la naturaleza y su capacidad para plasmarla con toda su vitalidad, aludiendo también al famoso fragmento de su biografía que aparece como colofón del primer volumen de su obra las Cien vistas del monte Fuji. ${ }^{33}$ No solo le atribuye ser el mejor representante del género "naturalista" sino que, basándose en la lectura de las obras del crítico de arte francés Gustave Geffroy $(1855-1926),{ }^{34}$ señala que la obra de Hokusai fue superior a la de otros grandes artistas del género ukiyo-e, reconociendo el trasfondo filosófico de su obra y asemejándolo a lo que en Occidente pudiéramos denominar genio. ${ }^{35}$ No obstante, siguiendo al historiador del arte Louis Gonse (1846 -1921) ${ }^{36}$ señala que el arte de Japón estaba perdiendo su carácter propio como fruto de su proceso de modernización bajo el influjo de Occidente. ${ }^{37}$ Sin embargo, sabemos que esta afirmación no fue del todo cierta, ya que lo que ocurrió fue una evolución de los medios más tradicionales, conservándose de alguna manera en el fondo la esencia nipona. De hecho, en el periodo Meiji el arte de la estampa evolucionó y dio lugar a otros grandes creadores continuadores del género ukiyo-e que utilizaron diferentes soportes, formatos o incluso aplicaron pigmentaciones que hasta entonces no habían sido utilizadas.

Hay que decir que a Hokusai se le tendió a comprar con creadores de primer orden del arte europeo llegándosele a denominar incluso "el Miguel Ángel de Japón”. 38 Como acabamos de advertir en noticias anteriores, el colofón aparecido en el primer volumen de sus Cien vistas del monte Fuji va a ser incluido en multitud de artículos cada vez que se trate a Hokusai. Ejemplo de ello es el artículo publicado en La Vanguardia también en $1904,{ }^{39}$ en el cual se va a repetir este fragmento pero redactado de diferente manera que el anterior. Seguramente este tipo de erratas y disparidades se debe a la falta de conocimiento del lenguaje nipón y a que la mayoría de datos habrían sido tomados de las traducciones de libros generados desde la historia del arte y la crítica francesas. El objetivo del citado artículo de La Vanguardia "La edad del genio", era debatir en qué momento empezaron su creatividad los grandes ar-

Ibidem.

Ibidem.

Probablemente las obras: Geffroy, G. (1890): 104. Geffroy, G. (1893): 143-147.

Gómez Carrillo, E. (1904): "Los pintores...”, op. cit., p. 3.

Gonse, L. (1883).

Gómez Carrillo, E. (1904): "Los pintores...”, op. cit., p. 3.

38 Anónimo (1904): "El imperio del Japón”, Nuevo Mundo, Madrid,10/03/1904. Artículo recogido en: Almazán, D. (2000): Japón y el japonismo..., op. cit., p.63.

39 Anónimo (1904): "La edad del genio", La Vanguardia, Barcelona, 24/03/1904, p. 2. 
tistas que en Occidente habían sido elevados a la categoría de "genios". Entre estos el autor cita a Saint Saens, Dubois, Gerómes, Roffaelli, Tattegrain, Fritz Thaulow o Rodin y también a Hokusai como representante de Oriente y como el auténtico genio creativo. Este mismo artículo fue reproducido en el periódico La Opinión de Santa Cruz de Tenerife; ${ }^{40}$ favoreciendo de esta manera la difusión de la obra del pintor japonés. También en 1904 se publicó el artículo "Art japones" en el Baluart de Sitges. ${ }^{41}$ En él se comenta cómo los titulares de los periódicos comenzaron a interesarse por la guerra ruso- japonesa (1904-1905) y cómo el arte japonés tuvo una recepción favorable en el París de la época, mencionando a otros importantes artistas del Japón como Okumura Masanobu (1686-1764) o Utagawa Kuniyoshi (1797-1861) que hasta entonces habían ocupado un lugar más secundario en la historia del grabado japonés. ${ }^{42}$ Por supuesto menciona a Hokusai, haciendo referencia en este caso a la faceta caricaturesca y humorística que presentaban sus obras. ${ }^{43}$ Además, en el artículo se reproducen algunos dibujos que se atribuyen a la figura del creador nipón y que subrayarían su maestría con la línea. ${ }^{44}$ Este último tema, el del humor, dará mucho juego también a los escritores de la época. Así, en este prolífico año de 1904, volvemos a tener un testimonio que alude a esta faceta caricaturesca en la revista La Ilustración obrera. ${ }^{45}$ En el artículo, titulado "La pintura y el dibujo en el Japón", se realiza un recorrido por la "génesis" de la pintura nipona en el que queda patente la afición de los japoneses por la caricatura. Se dice que el origen de la pintura japonesa es muy antiguo y se realiza un esbozo de la evolución de su pintura con algunos errores terminológicos y conceptuales hasta llegar al siglo XVIII, donde destaca acertadamente la figura de Ōgata Kōrin (1657-1716) y, por supuesto, a Hokusai ya entrado el siglo XIX. ${ }^{46}$ Se aprecia esa constante en la que Hokusai Katsushika se corona como el más alto eslabón dentro de la jerarquía de la llamada "escuela popular" o "vulgar", actualmente conocida como género ukiyo-e. Sin embargo, lo interesante de esta noticia es que se hace hincapié en un aspecto que hasta entonces había sido menos tratado como es el rasgo humorístico que presentan algunas de sus obras, en parte derivado de ese naturalismo con que el genio nipón percibía el mundo que le rodeaba.

En 1905 Ricardo Blanco-Belmonte, publicó en La Ilustración Española y Americana una presentación de las artes plásticas japonesas y sus modernas tendencias. Resaltando a Hokusai en el apartado dedicado al ukiyo-e, denominando al creador como el "rey del arte pictórico" ${ }^{47}$ Además, para ese mismo año también aparece en la revista Alrededor del Mundo ${ }^{48}$ un grabado de su serie Kana dehon Chûshingura (1806) atribuido erróneamente a Hiroshige.

Al año siguiente, en 1906, también encontramos en las publicaciones periódicas grabados pertenecientes al creador nipón como "Crisantemos y claveles" realizado

\footnotetext{
Anónimo (1904): “La edad del genio”, La Opinión, Santa Cruz de Tenerife, 02/05/1904, p. 2.

Quiquet (1904): “Art japonés”, Baluart de Sitges, Sitges, 24/04/1904, pp. 1-2.

Ibidem.

43 Ibidem.

44 Algunos de los dibujos representados en el artículo pertenecen a los volúmenes tercero y sexto de su obra Manga (1814-1878).

45 Anónimo (1904): “La pintura y el dibujo en el Japón”, La ilustración obrera, Barcelona, 30/07/1904, p. 375.

46 Ibidem.

47 Blanco-Belmonte, R. (1905): “El arte japonés”, La ilustración Española y Americana, Madrid, 15/01/1905, pp. 28-29. Artículo recogido en: Almazán, D. (2000): Japón y el japonismo..., op. cit., p. 63.

48 Anónimo (1905): "La tragedia de los Ronis. Un episodio dramático de la historia de Japón", Alrededor del Mundo, Madrid, 01/06/1905. Artículo recogido en: Almazán, D. (2000): Japón y el japonismo..., op. cit., p.63.
} 
en torno a 1830, en este caso para ilustrar un artículo de ikebana. ${ }^{49} \mathrm{~A}$ parte de estas reproducciones hay que destacar que la comparativa de Hokusai con grandes figuras del arte nacional fue uno de los temas más recurrentes. Este es el caso que observamos en La Lectura ${ }^{50}$ en un texto publicado por Emilia Pardo Bazán (1851-1921), en el que se dedican extensos párrafos a la figura de Goya. ${ }^{51}$ Es interesante como la autora equipara la vida de uno de nuestros grandes artistas con la de Hokusai, elevándolo así a la categoría de genio universal. Se podría decir que por meras casualidades ambos fueron figuras clave para el desarrollo y la renovación estética de sus respectivas naciones y épocas, y, a posteriori, para el arte universal. Por tanto, la mención de Hokusai en este artículo refuerza la idea de genialidad que se le atribuía con anterioridad desde el ámbito español. En esta comparación de nuevo se aprecia la referencia a la biografía del japonés, esta vez de una manera mucho más sintética, aludiendo a la línea final de su famoso colofón en el que señala que será capaz de dar vida solo a través de "la línea y el punto". Pero desde luego, y ante todo, un genio debía de realizar grandes logros para ser considerado como tal. Así se afirma en un artículo de 1907 el cual apareció en la revista de reportajes Alrededor del Mundo, que nos habla sobre "el cuadro mayor del mundo", atribuyendo tal proeza al creador nipón. ${ }^{52}$ La noticia, que aparece ilustrada, dice que, a partir de unas críticas que llegaron a los oídos del artista afirmando que solo podía pintar cosas pequeñas, se dispuso a realizar junto a sus discípulos el mayor cuadro del mundo [fig. 2]. ${ }^{53}$

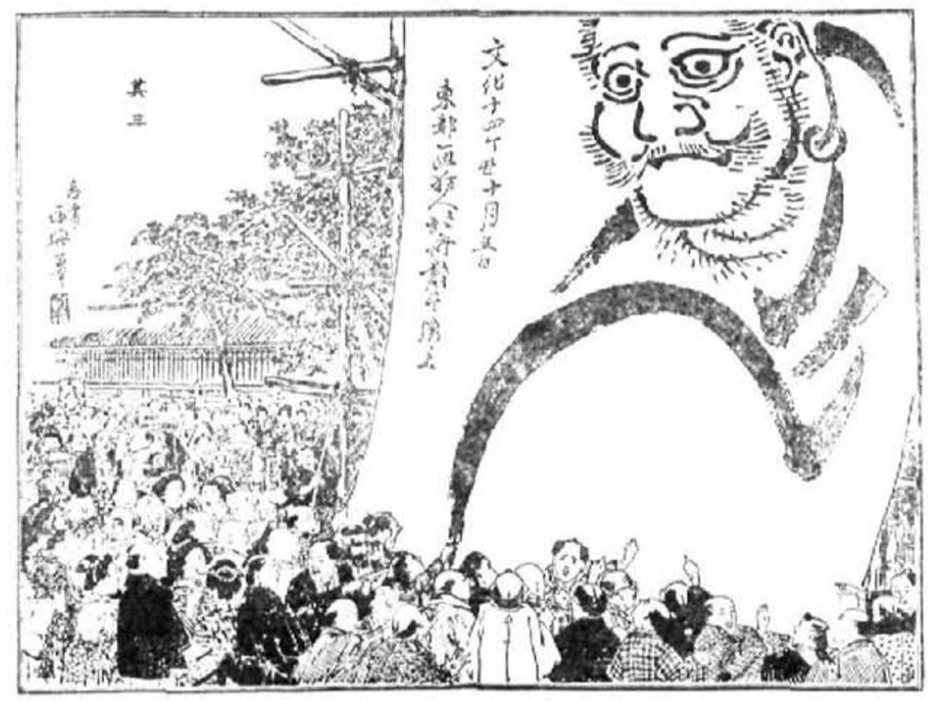

Fig. 2: "El cuadro terminado y expuesto al público. (De un libro japonés)", Alrededor del Mundo, Madrid, n. ${ }^{\circ}$ 405, 06/03/1907, p. 157.

49 Anónimo (1906): "El arte de las flores en el Japón”, Alrededor del Mundo, Madrid, 05/04/1906, pp. $220-221$. Artículo recogido en: Almazán, D. (2000): Japón y el japonismo..., op. cit., p.64.

50 Pardo Bazán, E. (1906): “Goya”, La Lectura, Madrid, 01/05/1906, p. 252.

51 Ibidem.

52 Anónimo (1907): "El cuadro mayor del mundo", Alrededor del Mundo, Madrid, 06/03/1907, p. 157. Artículo recogido en: Almazán, D. (2000): Japón y el japonismo..., op. cit., p.64.

53 Podemos encontrar bocetos de cómo era estéticamente esta creación para hacernos idea de su aspecto. Apareció representada en Periódico para la pintura gigante de Bodhidharma realizada en 1817, firmada como Hoku- 
Esta obra, una imagen de Daruma, importante patriarca del Budismo Zen, se cree que fue pintada junto a un templo y que medía 195 metros de lienzo.

Hubo gran expectación hacia esta pieza de Hokusai. Corrían rumores de que pintaba andando sobre el papel, describiéndose con exactitud el procedimiento para la realización de misma. En el artículo se dice que no existía en el mundo un cuadro más grande que el pintado por Hokusai, al que se ensalza como gran genio. ${ }^{54}$

Así pues, aparece en esta revista una nueva mención a la obra denominada hoy día como Manga, y además se reprodujo un recorte de la página doce del tomo primero en la que se muestran los diferentes tipos oficios. También en el artículo se decía que fue el autor de la obra más pequeña del globo, dos dibujos hechos sobre dos granos de arroz en el que uno representaba a un guerrero y otro a una pareja de gorriones. Asimismo, en el texto se aportan otros datos que suponen un claro avance con respecto a los artículos anteriores. En primer lugar, se establece una cronología correcta de su vida, y en segundo lugar se desvela el pseudónimo que adoptó al final de su carrera "El viejo chiflado por el dibujo", hecho que ocurrió tras pintar sus series más famosas como Treinta y seis vistas del monte Fuji, Mil vistas del mar o Cascadas en diferentes provincias. ${ }^{55}$

Tres años más tarde, en 1910, encontramos otro artículo que hace referencia al Manga en el que aparece representado un soldado agarrado a una viga. ${ }^{56}$

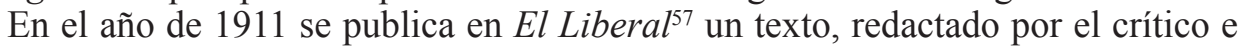
historiador del arte Rafael Doménech (1874-1929) que fue director del Museo de Artes Industriales de Madrid en el que de nuevo se menciona a Hokusai Katsushika, equiparándolo una vez más con grandes maestros del arte europeo. Así lo compara con Tiziano y con el pintor valenciano Antonio Muñoz Degrain (1840-1924), ${ }^{58}$ muy en boga por entonces, el cual realizó una ingente producción de paisajes, llenos de luz y color y que contó con el incondicional apoyo de Doménech. ${ }^{59}$ Pero en este artículo, aparte de estas comparaciones, se aportan más valoraciones sobre el creador nipón. Concretamente se vuelve a hacer hincapié en su especial capacidad para representar la naturaleza en su plenitud, recurriendo de nuevo al escrito que aparece en sus Cien vistas del monte Fuji, esta vez presentado de forma completa y con una traducción que se asemeja mucho a la que conocemos en la actualidad. ${ }^{60}$

Un año después, en 1912, finaliza la era Meiji (1868-1912) con la muerte del monarca Mutsuhito dando paso a la era Taishō (1912-1926), siendo esta una noticia que tuvo una gran repercusión en los medios de comunicación nacionales e internacio-

sai Taito y ejecutada con la técnica xilográfica japonesa. Otro testimonio es el que realiza Kōriki Tanenobu (Enkōan) (+1831) en su obra Álbum de bocetos de una actuación de pintura improvisada realizada también en 1817 y con la misma técnica que la anterior. Yonemura, A. (2006).

54 Anónimo (1907): "El cuadro mayor ...", op. cit., p. 157.

55 Anónimo (1907): "El cuadro mayor...", op. cit, p. 157.

56 Anónimo (1910): “Gente que trabaja con los pies", Alrededor del Mundo, Madrid, 08/06/1910, pp. 455-456. Artículo recogido en: Almazán, D. (2000): Japón y el japonismo..., op. cit., p.64.

57 Doménech, R. (1911): “La vida artística: los pintores de Carlos V y Felipe II”, El liberal, Madrid, 15/12/1911, p. 2.

58 Bonet, V. (1994).

59 De hecho, en 1915 publicó otro artículo sobre este artista. Doménech, R. (1915): “Información general de bellas artes. La exposición: Muñoz Degraín”, $A B C$, Madrid, 02/06/1915, p. 14. donde vuelve a compararlo con grandes artistas, incluido Hokusai. Y lo mismo hizo en 1922. Doménech, R. (1922): "Exposiciones de arte", $A B C$, Madrid, $n^{\circ}$ extraordinario, 16/07/1922, p. 15.

60 Ibidem, p. 2. 
nales. Para estas fechas en El Liberal ${ }^{61}$ encontramos que Gómez Carrillo publicó un artículo referente a la figura del dibujante, ilustrador y caricaturista español Joaquín Xaudaró (1872-1933), ${ }^{62}$ al que compara con Hokusai. Una de las facetas que más se resaltan del pintor nipón es su genialidad para el dibujo y sus continuas ansias de aprender. ${ }^{63}$ Esta habilidad fue también una de las características de Xaudaró quien además, como Hokusai con su Manga, publicó un manual didáctico titulado Método por el cual recibió un gran reconocimiento en la Escuela de Bellas Artes de París donde trabajó.

Iniciada la era Taishō (1912-1916), concretamente en 1913, encontramos un salto cualitativo en las informaciones sobre el arte japonés, gracias a las notables aportaciones del citado Rafael Doménech en el periódico $A B C^{64}$ en los que aparece Hokusai. La sección fue titulada "Notas de Arte. Japonismo: cartas a un pintor" y en ella el redactor establece una correspondencia ficticia con el "señor M.", posiblemente el ceramista Gregorio Muñoz Dueñas (18??- 1929), ${ }^{65}$ hombre enamorado de lo castizo, al cual le intenta explicar como el arte japonés por su maestría y perfección debía de ser una fuente más para el arte occidental. Con esa excusa trata multitud de aspectos relativos a la naturaleza, la estética y la influencia nipona, si bien el verdadero protagonista será el pintor japonés Hokusai Katsushika. En estos artículos habla de su producción, pero sobre todo subraya la importancia de su obra Manga. ${ }^{66}$

La obra de Hokusai marcó un antes y un después en los estudiosos de Oriente. Las referencias al Manga van a ser abundantes y desde luego se consolidará como una obra clave para cualquier pintor de la época que quiera renovar su imaginario iconográfico. Para muchos críticos, artistas e intelectuales dicha obra constituía una especie de compendio de vida y naturaleza, en el que el pintor nipón plasma con su preciso dibujo y gran sentido del humor todo tipo de actitudes y de detalles extraídos de manera directa del entorno que le rodeaba. Todo este imaginario desarrollado por uno de los mayores renovadores del género ukiyo-e debería de ayudar, según Doménech, a la mejor comprensión de las artes decorativas y a la renovación de un arte que ansiaba encontrar nuevos cauces. ${ }^{67}$ Pero el entusiasmo por parte de Doménech no se quedó en una difusión superficial del arte japonés sino que, como buen conocedor del mismo, se preocupó en profundizar e ir un poco más allá, adentrándose de manera más concreta en la producción de Hokusai y mencionando obras menos conocidas para el gran público como El libro de dibujos a dos pinceles o Colección de dibujos hechos con un solo golpe de pincel. ${ }^{68}$

\footnotetext{
Gómez Carrillo, E. (1912): “París: Monsieur Xaudaró, professeur” El Liberal, Madrid, 15/12/1912, p. 3.

Almazán, D. (1998).

Gómez Carrillo, E. (1912): "París: Monsieur...”, opus cit., p. 3.

64 Doménech, R. (1913): "Notas de Arte. Japonismo: cartas a un pintor", $A B C$, Madrid, 01/08/1913, p. 5.

Doménech, R. (1913): "Notas de Arte. Japonismo, cartas a un pintor”, $A B C$, Madrid, 4/08/1913, p. 8.

Doménech, R. (1913): "Notas de Arte. Japonismo: cartas a un pintor", $A B C$, Madrid, 26/08/1913, p. 4.

Doménech, R. (1913): "Notas de Arte. Japonismo: cartas a un pintor", $A B C$, Madrid, 30/08/1913, p. 6.

Doménech, R. (1913): “Notas de Arte. Japonismo: cartas a un pintor”, $A B C$, Madrid, 5/09/1913, p. 7.

Doménech, R. (1913): "Notas de Arte. Japonismo: cartas a un pintor”, $A B C$, Madrid, 18/10/1913, p. 8.

65 Ambos eran amigos y trabajaron juntos en distintos proyectos como la redacción de la obra: Doménech, R./

Muñoz Dueñas, G. / Pérez-Dolz, F. (1920).

66 Doménech, R. (1913): "Notas de Arte...", op. cit., 01/08/1913, p. 5.

67 Doménech, R. (1913): "Notas de Arte...", op. cit., 26/08/1913, p. 4.

68 Doménech, R. (1913): "Notas de Arte...", op. cit., 04/08/1913, p. 8.
} 
Asimismo, en esta serie de artículos se desprende una dura crítica hacia el arte académico y hacia los nuevos medios de reproducción múltiple como la fotografía (poco aceptada en los círculos artísticos de entonces). Frente a ello, contrapone las obras de artistas nipones que van a ser esenciales en la renovación estética del Viejo Continente. Un referente para que los creadores que estén a la vanguardia puedan romper con el academicismo y las viejas tradiciones que tenían, en gran parte, al arte subyugado bajo unas directrices que parecían inamovibles. El descubrimiento de figuras como Utamaro, Hokusai o Hiroshige fueron la causa de que nuestro arte tomase otro rumbo y que se produjera una amplitud de miras. ${ }^{69}$

Como vemos, los artículos de la época no solo fijaron la atención en Hokusai. Parece ser que, a estas alturas, los estudiosos y conocedores de la estética nipona querían ampliar el conocimiento del gran público. Así, en 1914 la revista Nova publicó un artículo del artista y crítico de arte Feliu Elias i Bracons (1878-1948), conocido por el pseudónimo "Joan Sacs", ${ }^{70}$ quien intentó expandir la mirada de los lectores más allá de las figuras tradicionales y del género ukiyo-e. Sacs hace un repaso sobre la pintura moderna japonesa y menciona la relación de nuestro maestro nipón con una figura clave para la comprensión y evolución de la estampa japonesa: Shiba Kokan (1747-1818), uno de los primeros artistas del archipiélago nipón que se dejó influenciar por la perspectiva occidental heredera de modelos renacentistas. ${ }^{71}$ Efectivamente es un hecho constatado que Hokusai se inspiró en la obra de Shiba Kokan para dar un giro a su estilo en relación a sus composiciones. El resultado de su influjo son obras que parecen haber sido realizadas con una mayor coherencia compositiva como El santuario del templo Juniso en Yotsuna, Edo o también Fuegos artificiales en el puente de Ryogoku. Asimismo, en unos meses después, "Sacs" vuelve a publicar en la misma revista un artículo monográfico sobre la "escuela Tosa" donde se nos brinda una visión de su génesis y desarrollo.72 Lo realmente interesante es como se desprende del texto la necesidad de apreciar otras manifestaciones artísticas de Japón y romper con la idea de que este arte solo ofrece las obras de los autores ukiyo-e. ${ }^{73}$

Unos años más tarde, en la revista de reportajes Summa bajo el título "La estampa japonesa" de nuevo Rafael Domenech nos brinda en 1916 uno de los textos más interesantes relativos al grabado ukiyo-e. ${ }^{74}$ En este texto se incide en los libros ilustrados más antiguos del siglo XVI y en las estampas del siglo XVII. Nuestro erudito hará hincapié en el interés de Torii Kiyonobu (1664-1729) y en el surgimiento del color en el siglo XVIII que se hizo característico del "Oukiyo-ye” o escuela popular. Además, en el artículo también se analiza el procedimiento utilizado para la realización de las estampas. Sin embargo, lo que nos llama más la atención es que aparece una de las primeras traducciones al castellano de la palabra ukiyo-e o "pinturas del mundo flotante"; tomada en este caso de una de las obras realizadas por el crítico francés Edmundo de Goncourt (1822-1896), autor de gran número de trabajos sobre arte nipón, en la que ya se refiere a esa idea de transitoriedad y de mundo pasajero. ${ }^{75}$

\footnotetext{
Doménech, R. (1913): “Notas de arte...”, op. cit., 18/10/1913, p. 8.

Sacs, J. (1914): "La pintura moderna japonesa", Nova, Barcelona, 27/08/1914, p. 6.

Ibidem.

Sacs, J. (1914): "L' escola japonesa "Toça" de pintura", Nova, Barcelona, 15/10/1914, pp. 3-4.

Ibidem.

Doménech, R. (1916): “La estampa japonesa”, Summa, Madrid, 15/01/1916, pp. 42-44.

Ibidem.
} 
Por supuesto, no podía dejar de mencionar a Hokusai y a otras figuras muy reconocidas que tuvieron desde el descubrimiento del arte nipón una gran trascendencia. Se dice que las obras de los artistas "Oukiyo-ye” fueron las que abrieron al mundo occidental la admiración por el arte japonés. Eso sí, coincidiendo con "Sacs", afirma que durante muchos años se creyó que el esplendor de Japón estaba en este tipo de arte, una opinión que se está revelando como falsa. ${ }^{76}$

Por último, en su contenido hay otra información a destacar. El autor nos habla de las figuras que ayudaron al descubrimiento, conocimiento y propagación del arte japonés; aportándonos una lista de nombres clasificados por nacionalidades que hoy día han sido estudiados y se ha corroborado que fueron esenciales en esta labor. ${ }^{77}$

En 1918 el mencionado "Sacs" vuelve a ensalzar la figura de Hokusai en un nuevo artículo publicado en Vell i Nou. ${ }^{78}$ En esta ocasión Hokusai se alza como el maestro irrefutable de la observación y del dibujo, recalcándose la idea de su habilidad para la copia del natural y la percepción del entorno. ${ }^{79}$ En la misma línea de reivindicación tanto de Hokusai como de otros autores de arte japonés, tenemos un artículo publicado en 1919 en la revista catalana Vell i Nou ${ }^{80}$ Se dedica de forma completa a la figura de Totoya Hokkei (1780-1850), uno de los primeros discípulos de Katsushika Hokusai y que más fortuna crítica tuvo en la época del japonismo; subrayándose la similitud existente entre la obra del maestro nipón y su discípulo (que presentaba mayor gracia y feminidad frente al primero), estableciendo así conexiones directas en sus producciones.

Pero el arte japonés no solo se difundió a través de textos publicados en la prensa. Tenemos testimonios de que se realizaron conferencias sobre el tema que propagaron su conocimiento y que fueron impartidas por eminentes eruditos. Este fue el caso del ya citado Rafael Doménech, cuya sabiduría con respecto a la materia era abundante como hemos señalado anteriormente. En 1921 Doménech impartió una conferencia en el Museo de Artes Industriales que fue cubierta por los medios y la prensa del momento; así el periódico de La Época ${ }^{81}$ recoge dicho testimonio. Dice el artículo que en su conferencia señaló que hablar de arte japonés es hablar del gran refinamiento producido por Oriente. También en su discurso no faltó un apartado sobre la figura del gran genio japonés Hokusai. Para Doménech había dos características que son exclusivas del arte japonés: la sensibilidad refinada y el amor por la naturaleza, nota esta última en la que sobresalieron los dos grandes maestros del género ukiyo-e del siglo XIX Hokusai y Hiroshige. Además, añade otra serie de cualidades de este singular arte como son el espíritu de observación y la poesía. ${ }^{82} \mathrm{El} A B C^{83}$ también cubrió esta conferencia de Rafael Doménech en un artículo que podríamos entender como un complemento del de La Época ${ }^{84}$ debido a que aporta otros aspectos de la charla. Se menciona que en el discurso del erudito ensalzó especialmente a nuestro genio

Ibidem.

Ibidem.

Sacs, J. (1918): "El Sant Joan Evangelista de la col.lecció Fuço”, Vell i Nou, Barcelona, 15/04/1918, p. 149.

Ibidem.

Anónimo (1919): “Hokkei”, Vell i Nou, Barcelona, 15/04/1919, pp.149-150.

81 Anónimo (1921): “Conferencias: El señor Doménech en el Museo de Artes Industriales”, La Época, Madrid, 23/03/1921, p. 2.

82 Ibidem.

83 Anónimo (1921): "Lecturas y conferencias: La decoración japonesa”, $A B C$, Madrid, 23/03/1921, pp. 13-14.

84 Anónimo (1921): “Conferencias: El señor Domenech...”, op. cit., p. 2. 
nipón por su capacidad de plasmar en su obra la naturaleza. ${ }^{85}$ Asimismo, se señala que incluyó de nuevo el famoso colofón autobiográfico del primer volumen de las Cien vistas del monte Fuji para que el gran público se hiciera una idea de la actitud vital y ética del creador japonés en relación a sus aspiraciones artísticas. ${ }^{86}$

Ya en 1923 el arte japonés y la figura de Hokusai no son unos completos desconocidos $\mathrm{y}$, de hecho, ya hemos podido percibir cómo el número de artículos sobre el tema aumentaron con el paso del tiempo. Este año se publica un texto en el Almanaque Bailly-Bailliere que de nuevo trata el tema de los grabados japoneses. ${ }^{87} \mathrm{En}$ su contenido se hace un recorrido por la "escuela popular japonesa" ukiyo-e, nombrando a sus principales autores desde su creación en el siglo XVII aparte de Hiroshige y Hokusai. En el texto Hokusai juega un papel fundamental, subrayándose el realismo y la expresión que lo identifican. Llama la atención que su sobrenombre de "viejo loco de los dibujos" aparezca como algo relevante. Eso sí, es curioso observar que pese al incremento del tratamiento de los temas japoneses en las publicaciones periódicas de nuestro país, todavía no hay un consenso establecido para denominar o transcribir los nombres japoneses, tal y como se evidencia al ver la transcripción de los nombres propios en los artistas e incluso al denominar al monte Fuji, uno de los mayores mitos del imaginario sobre Japón en Occidente, el cual se escribe como "Fugi" ${ }^{88}$ También en el artículo se trata la figura de Hiroshige (1797-1858), diciendo que sus representaciones son más naturalistas y que se asemejan más a la visión europea. El autor concluye señalado el cambio de rumbo que el arte japonés está viviendo desde finales del siglo XIX durante la Era Meiji (1868-1912) y que continua en la Era Taishō (1912-1926), fruto de su acelerada modernización y occidentalización. Sus palabras son un testimonio muy valioso, ya que nos dicen que en España éramos conscientes de que el País del Sol Naciente estaba inmerso en un proceso de transformación. Esta apertura de Japón hacia el mundo generó un rechazo dirigido a la cultura tradicional del archipiélago en boga de los saberes y estéticas que procedían de Occidente, refiriéndose así a Hokusai e Hiroshige.$^{89}$ Este texto fue ilustrado con algunas obras de Hokusai: La gran ola de Kanagawa, Tormenta bajo la cumbre y Pájaros en la nieve. ${ }^{90}$ Además ese mismo año en la revista $L$ a Esfera ${ }^{91}$ Hokusai y Utamaro compartieron noticia en una presentación general relacionada con el gran terremoto del año 1923 ocurrido en el archipiélago nipón. Otras publicaciones de la época también se hicieron eco de las genialidades del artista japonés, ya que de nuevo en Alrededor del Mundo se volvieron a reproducir imágenes del Manga ${ }^{92}$ y de su serie Shika Shashin-kyō..$^{93}$

También grandes figuras del panorama literario español hicieron referencia al creador nipón. Este es el caso de Ramón Gómez de la Serna (1888-1963), ${ }^{94}$ uno de

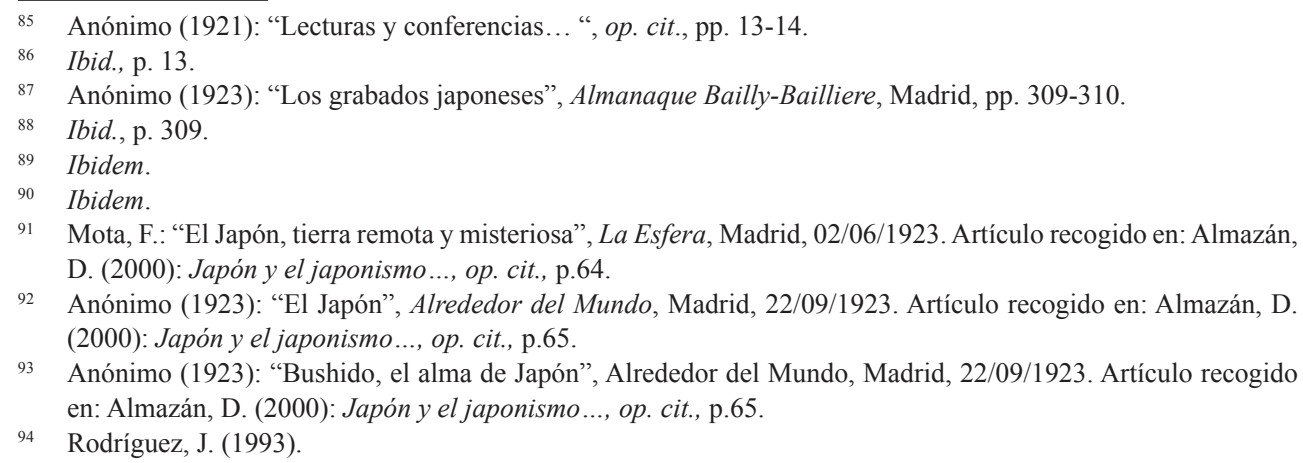


los autores del movimiento novecentista y que más relevancia tuvo en el ámbito nacional a principios del siglo XX. Como testimonio de su conocimiento sobre Japón tenemos un artículo que publicó en 1923 entre las páginas de la revista $\mathrm{El} \mathrm{Sol},{ }^{95}$ en el cual profundiza en la obra del caricaturista y periodista Massaguer (1889-1965), ${ }^{96}$ haciendo un análisis de su dibujo desde un punto de vista personal cargado de subjetividad. En este texto incluye un párrafo en el que se realiza una analogía entre la producción del dibujante y los grandes artistas del ukiyo-e. ${ }^{97}$

Hemos visto hasta el momento publicaciones periódicas que tenían sus editoriales en grandes ciudades como pueden ser Madrid o Barcelona a modo de dos focos claramente diferenciados. La interrelación entre estos dos puntos clave y el conocimiento que divulgaban en lo relativo a la cultura nipona y en concreto al arte japonés consiguió que su admiración se propagase a otros lugares de nuestra geografía. De esta forma el fenómeno del japonismo, la moda por el arte japonés y concretamente las obras de Hokusai llegaron a territorios más periféricos, donde también se suscitó el interés por estos temas. Un claro ejemplo es el de la revista Flores y abejas editada en Guadalajara, ya que tuvo un carácter más local a la hora de su difusión. En uno de los números, publicado en $1923,{ }^{98}$ se nos presenta un artículo redactado por el arqueólogo y pintor aragonés Ramiro Ros Ráfales (1871-1927), que trata sobre el arte del País del Sol Naciente. La excusa para abordar el tema fue la erupción del Fuji sucedida ese mismo año que es comparada con la catástrofe de Pompeya. En este contexto, el autor se pregunta qué habrá sido del arte incendiado en los museos. ${ }^{99}$ Por supuesto a Ros Ráfales le preocupa el destino de la obra de Hokusai. Pese al paso del tiempo y a las noticias que habían ido aportando informaciones sobre otros artistas japoneses, parece que la fortuna crítica que había cosechado Hokusai desde la llegada del arte nipón a Europa todavía le colocaba en un puesto superior. ${ }^{100}$ Desde luego, este párrafo intenta consagrar al genio japonés como el iniciador del género popular de la xilografía a color, pero esto no fue así. Posiblemente el artista que inauguró este tipo de estampación fue Hishikawa Moronobu (1618-1694) en el siglo XVII, ya que estaba instruido en los oficios de la pintura, la xilografía y la impresión, siendo actualmente esta figura la más aceptada por la comunidad científica como pionero del género. Hokusai es considerado en realidad más bien como un artista renovador del género gracias a sus atrevidas composiciones, temáticas y coloraciones. Lo que sí que es relevante es la cita a piezas que remiten sus series más famosas y que reflejan el amor por la naturaleza del pueblo japonés que, según el autor del artículo, ha inspirado sus leyes de protección al medio ambiente.

También en el año 1923 se publicó otro artículo en el periódico $A B C$ del citado Enrique Gómez Carrillo, ${ }^{101}$ en el que rememora sus vivencias en el país nipón durante el viaje que realizó en 1905 y hace un sugerente reportaje del ambiente que él pudo percibir en el Tokio de la era Meiji a principios del siglo XX. Recalca el impacto que esta ciudad causaba a los visitantes llegados de todas las partes del mundo gracias al ajetreo callejero y al sin fin de objetos curiosos, tejidos y accesorios como los vinculados a

\footnotetext{
95 Gómez De La Serna, R. (1923): “La vida: el guiñol de Massaguer”, El Sol, Madrid, 24/07/1923, p. 2.

96 Periodista y caricaturista de origen cubano. Consúltese: Rubira, R. (2011).

97 Gómez De La Serna, R. (1923): “La vida: ...”, op. cit., p. 2.

98 Ros Rafales, R. (1923): “De arte nipón”, Flores y abejas, Guadalajara, 16/09/1923, p. 2.

99 Ibidem.

100 Ibidem.

101 Gómez Carrillo, E. (1923): "Por las calles de Tokio", $A B C$, Madrid, 19/09/1923, p. 3.
} 
la ceremonia del té que envolvían la vida cotidiana nipona. Entre todo ese bombardeo informativo Gómez Carrillo utiliza su habilidad para hacer referencia al maestro nipón del dibujo, evocando su obra Manga a través de las diferentes figuras que aparecen en su relato. Es decir, nos presenta a Hokusai como aquel genio que fue capaz de recoger la más pura esencia de la sociedad japonesa, aquella que en un principio es intangible y que parece que en ningún momento va a poder encontrar un recipiente para que la contenga. En 1926 se publica otro artículo de Gómez Carrillo ${ }^{102}$ en el que hace referencia a la caricatura y el humor de la obra de Toño Salazar (1897-1986). ${ }^{103}$ Un caricaturista, ilustrador y diplomático salvadoreño que gozaba de gran prestigio en la época, el cual trabajó para importantes publicaciones del momento como Blanco y negro, La Razón, La Rire o Le Matin. Una vez más se realiza una analogía entre el caricaturista y el maestro nipón Hokusai, atribuyéndoles a ambos la capacidad de ser genios creadores con una invención y sed generadora inagotables. ${ }^{104}$

Finalmente, quisiéramos destacar el artículo publicado en 1926 en la revista de reportajes Revista del ateneo, editada en Jerez de la Frontera (Cádiz) con el título "La pintura japonesa: Hokusai". ${ }^{105}$ Redactado por el artista y grabador jerezano Teodoro Nicolás Miciano Becerra (1903-1974) ${ }^{106}$ es de los pocos textos editados por la prensa española que se dedica íntegramente a la figura del maestro nipón Katsushika Hokusai, destacando por su profundidad y por su discurso claro, ordenado y de carácter académico. El texto nos introduce de forma directa en una disyuntiva, afirmando contundentemente que la pintura japonesa es muy distinta a la occidental. Según el autor, este modelo de reproducir de memoria ha sido adoptado de forma reciente en las escuelas europeas más a la vanguardia. Posteriormente entra de lleno en la obra de Hokusai, al que considera una de las personificaciones del florecimiento del arte de Japón sobre otras grandes figuras: "Toyokumi, Utamaro, Hiroshigé, Shunsho, los Torii y otros, pero la gigantesca talla artística de Hokusai, le hace destacarse de todos ellos y originar encendidas alabanzas". ${ }^{107}$ Esta afirmación coincide con la opinión de otros autores que han manifestado esta percepción desde Occidente como Whistler, Edmundo de Goncourt o del historiador del arte inglés Stewart Dick, ${ }^{108}$ grandes conocedores del arte nipón. Se dice que "el arte de Hokusai es un prodigio de gracia, movimiento y originalidad"109 que presenta "un dibujo correctísimo de trazos rápidos, nerviosos y ondulantes", ${ }^{110}$ por ello "sus estampas y grabados seducen desde un primer momento" "111 ya que "todos los temas imaginables han sido tratados por él”. ${ }^{112}$ "Los diversos animales sorprendidos en sus más naturales actitudes" o "las composiciones con figuras" todo ello reflejado en obras como El robo de la gran campaña, Muchachas haciendo cortinas de bambú o Ghost vigilando un lecho de cortinas; menciona también los Chushingura (recopilación de escenas teatrales y

\footnotetext{
102 Gómez Carrillo, E. (1926): “Toño Salazar, príncipe de los caricaturistas”, $A B C$, Madrid, 29/06/1926, p. 3.

103 Huezo Mixco, M. (2005).

104 Gómez Carrillo, E. (1926): “Toño Salazar...”, op. cit., p.3.

105 Miciano, T. (1926): "La pintura japonesa: Hokusai”, Revista del ateneo, Jerez de la Frontera, 15/05/1926, p. 124-127.

106 Lafuente Ferrari, E. (1974).

107 Miciano, T. (1926): “La pintura japonesa...”, op. cit., pp. 124-125.

108 Autor de la obra: Stewart, D. (1906).

109 Miciano, T. (1926): “La pintura japonesa...”, op. cit., p. 125.

110 Ibidem.

111 Ibidem.

112 Ibidem.
} 
paisajes realizados en 1798), así como el Hokusai Gwashiki (publicado en 1819) y otros libros como Cien Poemas contados por el ama y Grandes flores e Imágenes de los poetas. También comenta el autor que "En el paisaje fué Hokusai una revelación para el arte japonés" 113 ya que logró exaltarlo a su máximo grado; prueba de ello son sus Cien vistas de Fuji (1835), donde cada grabado es único e irrepetible. Afirma asimismo que el maestro nipón rompió los antiguos moldes fijados en el género ukiyo-e porque "reproducía cuanto llegaba al alcance de su espíritu inquieto". $114 \mathrm{Se}$ nombra el "Ippitsugwafu" (Álbum de dibujos de un solo trazo) que luego daría lugar al "Mangwa". Esta última aparece en el texto como un compendio de la vida japonesa que presenta quince tomos y que el primero se publicó en 1812. Además, después de esta fantástica obra realizó su serie Treinta y seis vistas de Fuji. A continuación y para concluir, realiza una breve biografía del autor en la que ya nos aparecen datos muy concretos sobre sus peripecias vitales, su nacimiento y muerte, sus influencias (de quien fue discípulo), cuantas obras produjo a lo largo de su vida y que fue lo que le llevó a la fama (datos correctos a rasgos generales en su mayoría, aunque hay que decir que el Ippitsu Gafu se realizó unos años más tarde que la primera edición del Manga, concretamente en 1823; además la fecha en la que se editó por primera vez el Manga es 1814 y no 1812). Cierra nuestro autor el artículo con unos versos compuestos por el mismísimo artista que, según la costumbre japonesa, deberían de haberse grabado en su tumba: "Mi alma en fuego fatuo convertida. Vagar sabrá en la estación florida". ${ }^{115}$ Hay que mencionar también que a lo largo del texto se incluyen tres ilustraciones extraídas de las obras del creador nipón [fig. 3]. ${ }^{116}$

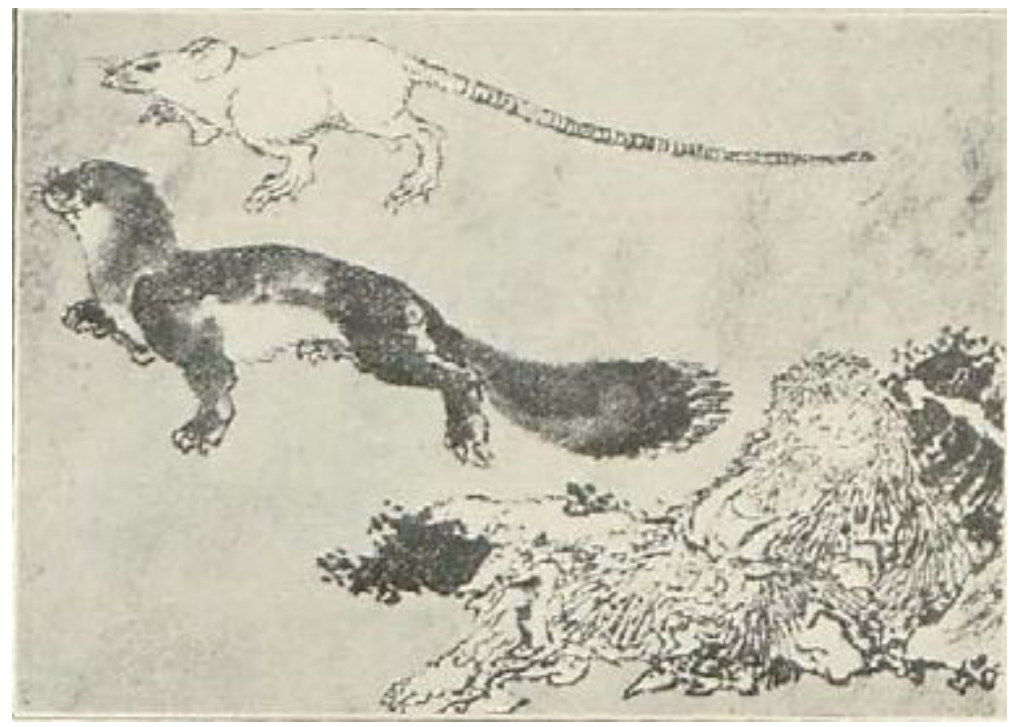

Fig. 3: "La pintura japonesa: Hokusai", Revista del ateneo, Jerez de la Frontera, 15/05/1926, p. 126.

\section{Ibidem.}

114 Ibid., p. 126.

115 Miciano, T. (1926): “La pintura japonesa...”, op. cit., p. 126.

116 Aparecen diversos dibujos atribuidos a Hokusai que no hemos podio localizar y un fragmento de su llamado Volumen 98. 
Tras analizar todas las fuentes localizadas a lo largo de esta investigación se puede afirmar que la cultura japonesa y en concreto la figura de Hokusai levantaron un gran interés intelectual desde su descubrimiento. Al principio, la visión que se tenía del creador japonés fue más sucinta, cometiéndose errores o lagunas en cuanto a las informaciones aportadas. Así pues y con el paso del tiempo, esta serie de errores iniciales se fueron subsanando gracias al interés que mostraban los eruditos de la época hacia este tipo de arte y la cantidad de información que llegaba a través de diversas vías. Como consecuencia se pudo conocer mejor la figura del genio japonés y su maestría, teniendo así una valoración crítica positiva cada vez más pujante. Este fenómeno hizo que surgieran auténticos expertos en el campo del arte japonés y del grabado ukiyo-e. Generándose así un panorama de difusión enorme que hacía que el gran público, lector de todo este tipo de prensa, conociera con bastante precisión la vida y obra de este pintor nipón. Todo este interés en su figura ayudó, sin lugar a dudas, al avance y transformación del arte de Occidente. Asimismo, la visión presentada en las publicaciones periódicas de finales del siglo XIX y primeras décadas del $\mathrm{XX}$ fue aquella en la que Hokusai se alzó preminentemente como un creador magistral, digno de excelencia, procedente de un lugar exótico y lejano. Esta legitimación otorgada al creador japonés que nos presenta la prensa española es esencial para la comprensión de las relaciones del País del Sol Naciente en España. Repercutiendo su visión de forma directa en los diversos círculos comerciales, artísticos y sociales que se encontraban en pleno auge a finales del siglo XIX y principios del XX en nuestro país.

\section{Bibliografía}

Almazán, David (1998): “El japonismo en la obra gráfica del ilustrador Joaquín Xaudaró (1872-1933)”. En: Gómez, José Antonio (ed.): Arte e identidades culturales. Oviedo: Universidad de Oviedo, pp. 41-30.

Almazán, David (2000): Japón y el japonismo en las revistas ilustradas españolas (18701935). Tesis doctoral dirigida por Elena Barlés Báguena, Departamento de Historia del Arte, Universidad de Zaragoza, 11 vols., vol. 3.

Anderson, William (1886): Descriptive and Historical Catalogue of a Collection of Japanese and Chinese Paintings in the British Museum. Londres: Longmans \& Co.

Anónimo (1883): "El arte japonés”, Diario oficial de avisos de Madrid, Madrid, 30/11/1883, p.3.

Anónimo (1884): “El arte japonés”, Diario oficial de avisos de Madrid, Madrid, 19/02/1884, p. 3.

Anónimo (1891): “El pintor japonés Hokusai”, La Ilustración Ibérica, Barcelona, 12/09/1891, p. 587.

Anónimo (1897): “Barcelona”, La Renaixensa, Barcelona, 07/01/1897, p. 129.

Anónimo (1897): “Barcelona”, La Renaixensa, Barcelona, no 7480, 09/01/1897, p. 171.

Anónimo (1902): “Los japoneses y el cabestrante", Alrededor del Mundo, Madrid, 13/02/1902, p. 113.

Anónimo (1902): “La solución”, Alrededor del Mundo, Madrid, 27/02/1902, p. 141.

Anónimo (1904): “El imperio del Japón”, Nuevo Mundo, Madrid,10/03/1904.

Anónimo (1904): “La edad del genio”, La Vanguardia, Barcelona, 24/03/1904, p. 2. 
Anónimo (1904): “La edad del genio", La Opinión, Santa Cruz de Tenerife, 02/05/1904, p. 2.

Anónimo (1904): "La pintura y el dibujo en el Japón”, La ilustración obrera, Barcelona, 30/07/1904, p. 375.

Anónimo (1905): "La tragedia de los Ronis. Un episodio dramático de la historia de Japón", Alrededor del Mundo, Madrid, 01/06/1905.

Anónimo (1906): "El arte de las flores en el Japón”, Alrededor del Mundo, Madrid, 05/04/1906, pp. 220-221.

Anónimo (1907): "El cuadro mayor del mundo", Alrededor del Mundo, Madrid, 06/03/1907, p. 157.

Anónimo (1910): “Gente que trabaja con los pies”, Alrededor del Mundo, Madrid, 08/06/1910, pp. 455-456.

Anónimo (1919): “Hokkei”, Vell i Nou, Barcelona, 15/04/1919, pp.149-150.

Anónimo (1921): “Conferencias: El señor Doménech en el Museo de Artes Industriales”, La Época, Madrid, 23/03/1921, p. 2.

Anónimo (1921): "Lecturas y conferencias: La decoración japonesa", $A B C$, Madrid, 23/03/1921, pp. 13-14.

Anónimo (1923): “Los grabados japoneses”, Almanaque Bailly-Bailliere, Madrid, pp. 309310.

Anónimo (1923): “El Japón”, Alrededor del Mundo, Madrid, 22/09/1923.

Anónimo (1923): “Bushido, el alma de Japón”, Alrededor del Mundo, Madrid, 22/09/1923.

Barlés, Elena (2010): "Relaciones artísticas y culturales entre España y Japón durante la segunda mitad del siglo XIX y primeras décadas del XX”. En: Bando, Sho Ji / Kawanari, Yo (eds.): Nihon Spain kōryūshi. Tokio: Renga Shobō, pp. 154-171.

Blanco-Belmonte, Ricardo (1905): "El arte japonés", La ilustración Española y Americana, Madrid, 15/01/1905, pp. 28-29.

Bonet, Victoria (1994): “Antonio Muñoz Degraín o la fascinación del color”. En: Saitabi: revista de la Facultat de Geografia i Història, n²44, Valencia, pp. 255-266.

Bru, Ricard (2008): “Els inicis del comerç d'art japonès a Barcelona 1868-1887”. En: Butlletí de la Reial Acadèmia Catalana de Belles Arts de Sant Jordi, 21. Barcelona.

Bru, Ricard (2011): "Ukiyo-e en Madrid. Las estampas japonesas del Museo Nacional de Arte Moderno y su legado en el Museo Nacional del Prado". En: Boletín del Museo del Prado, 19, 47, Madrid, pp. 153-170.

Doménech, Rafael (1911): "La vida artística: los pintores de Carlos V y Felipe II", El liberal, Madrid, 15/12/1911, p. 2.

Doménech, Rafael (1913): "Notas de Arte. Japonismo: cartas a un pintor", $A B C$, Madrid, 01/08/1913, p. 5.

Doménech, Rafael (1913): "Notas de arte. Japonismo, cartas a un pintor", $A B C$, Madrid, 4/08/1913, p. 8.

Doménech, Rafael (1913): "Notas de Arte. Japonismo: cartas a un pintor", $A B C$, Madrid, 26/08/1913, p. 4.

Doménech, Rafael (1913): "Notas de Arte. Japonismo: cartas a un pintor", $A B C$, Madrid, 30/08/1913, p. 6.

Doménech, Rafael (1913): "Notas de Arte. Japonismo: cartas a un pintor”, $A B C$, Madrid, 5/09/1913, p. 7.

Doménech, Rafael (1913): "Notas de arte. Japonismo: cartas a un pintor", $A B C$, Madrid, 18/10/1913, p. 8.

Doménech, Rafael (1915): “Información general de bellas artes. La exposición: Muñoz Degraín”, $A B C$, Madrid, 02/06/1915, p. 14 
Doménech, Rafael (1916): “La estampa japonesa”, Summa, Madrid, 15/01/1916, pp. 42-44.

Doménech, Rafael (1922): "Exposiciones de arte", $A B C$, Madrid, $\mathrm{n}^{\circ}$ extraordinario, 16/07/1922, p. 15

Doménech, Rafael/ Muñoz Dueñas, Gregorio / Pérez-Dolz, Francisco (1920): Tratado de técnica ornamental. Madrid: A. de Ángel Alcoy.

Europeana (2008): Europeana Collections [https://www.europeana.eu/portal/en], European Union's Connecting Europe Facility.

https://www.europeana.eu/portal/en/explore/people/50327-adolf-oberlander.html [Consulta: 18/10/2017].

Geffroy, Gustave (1890): “Les paysagistes japonais “, Le Japon artistique, n. ${ }^{\circ} 33$, vol. III, 1890, p. 104.

Geffroy, Gustave (1893) “Au Japon: les paysages d'Hiroshige, les femmes d'Outamaro.” La Grande dame 1, pp. 143-147.

Gómez De La Serna, Ramón (1923): “La vida: el guiñol de Massaguer”, El Sol, Madrid, 24/07/1923, p. 2.

Gonse, Louis (1883): L'art japonais. Paris: A. Quantin.

Gómez Carrillo, Enrique (1904): "Los pintores japoneses en el museo del Louvre”, El liberal, Madrid, 18/02/1904, p. 3.

Gómez Carrillo, Enrique (1912): “París: Monsieur Xaudaró, professeur” El Liberal, Madrid, 15 de diciembre de 1912, p. 3.

Gómez Carrillo, Enrique (1923): "Por las calles de Tokio", $A B C$, Madrid, 19/09/1923, p. 3.

Gómez Carrillo, Enrique (1926): “Toño Salazar, príncipe de los caricaturistas”, $A B C$, Madrid, 29/06/1926, p. 3.

Huezo Mixco, Miguel (2005): “Toño Salazar”. En: Guaraguao: revista de cultura latinoamericana, 9, 21, pp. 267-272.

Lafuente Ferrari, Enrique (1974): "Recuerdo de Teodoro Miciano (1903-1974)". En: Academia: Boletín de la Real Academia de Bellas Artes de San Fernando, 38, Madrid, Primer semestre, pp. 17-36.

Mencarini, Juan (1904): "El imperio del Japón”, Boletín de la real sociedad geográfica, Madrid, 01/01/1904, p. 44.

Miciano, Teodoro (1926): "La pintura japonesa: Hokusai”, Revista del ateneo, Jerez de la Frontera, 15/05/1926, p. 124-127.

Mota, F.: “El Japón, tierra remota y misteriosa", La Esfera, Madrid, 02/06/1923.

Pardo Bazán, Emilia (1906): “Goya”, La Lectura, Madrid, 01/05/1906, p. 252.

Pérez Caballero, Juan (1889): “Adiós al Japón”, El nuevo ateneo, Toledo, 15/11/1889, p. 137.

Pérez Caballero, Juan (1888): "Estudio práctico sobre nuestros intereses en el Japón según la base que ofrece la estadística general del comercio exterior del Imperio en el año 1887". En: Boletín de la Sociedad Geográfica de Madrid, Madrid, 1888, pp. 324-362.

Quiquet (1904): “Art japonés”, Baluart de Sitges, Sitges, 24/04/1904, pp. 1-2.

Rodríguez, Josep (1993): Ramón Gómez de la Serna: autobiografía y recurrencia. Tesis doctoral dirigida por Manuel Aznar Soler, Universidad Autónoma de Barcelona.

Ros Rafales, Ramiro (1923): “De arte nipón”, Flores y abejas, Guadalajara, 16/09/1923, p. 2.

Rubira, Rainer (2011): "Los usos comerciales de la caricatura en Cuba: Conrado Walter Massaguer y la revista "Cinelandia" como dispositivo para la construcción de la hegemonía del "star system" hollywoodense en la isla". En: Index.comunicación: Revista científica en el ámbito de la Comunicación Aplicada, vol. 1, 1, Universidad Rey Juan Carlos, pp. 145-169.

Sacs, Joan (1914): “La pintura moderna japonesa”, Nova, Barcelona, 27/08/1914, p. 6. 
Sacs, Joan (1914): “L' escola japonesa “Toça” de pintura”, Nova, Barcelona, 15/10/1914, pp. 3-4.

Sacs, Joan (1918): "El Sant Joan Evangelista de la col.lecció Fuço", Vell i Nou, Barcelona, 15/04/1918, p. 149.

Serrano, Javier (2006): “Solo, altivo y pobre: la polémica modernista de Valle-Inclán con Francisco Navarro Ledesma (1903)”. En: Moenia: Revista lucense de lingüistica y literatura., 12, Santiago de Compostela, pp. 129-156

Soriano, Rodrigo (1892): “Oberländer”, La época, Madrid, 05/06/1892, p. 2.

Spang, Christian / Wippich, Rolf-Harald (2007): Japanese-German Relations, 1895-1945: War, Diplomacy and Public Opinion. Nueva York: Routledge.

Stewart, Dick (1906): Arts and crafts of old Japan. Londres: T. N. Foulis.

Universidad Abierta de Cataluña (2014): Archivo China-España 1800-1950 [http://ace.uoc. $\mathrm{edu} / \mathrm{]}$

ALTER/UOC.http://ace.uoc.edu/exhibits/show/galeria-de-personajes/juan-mencarini [Consulta: $14 / 11 / 2017]$.

Yonemura, Ann (2006): Hokusai, vol.1. Washington: Smithsonian Institution. 